\title{
Improved production of secreted heterologous enzyme in Bacillus subtilis strain MGB874 via modification of glutamate metabolism and growth conditions
}

Kenji Manabe ${ }^{1,2 \dagger}$, Yasushi Kageyama ${ }^{1 \dagger}$, Takuya Morimoto ${ }^{1}$, Eri Shimizu ${ }^{3}$, Hiroki Takahashi ${ }^{4}$, Shigehiko Kanaya ${ }^{5}$, Katsutoshi Ara $^{6}$, Katsuya Ozaki ${ }^{{ }^{*}}$ and Naotake Ogasawara ${ }^{2 *}$

\begin{abstract}
Background: The Bacillus subtilis genome-reduced strain MGB874 exhibits enhanced production of exogenous extracellular enzymes under batch fermentation conditions. We predicted that deletion of the gene for RocG, a bi-functional protein that acts as a glutamate dehydrogenase and an indirect repressor of glutamate synthesis, would improve glutamate metabolism, leading to further increased enzyme production. However, deletion of rocG dramatically decreased production of the alkaline cellulase Egl-237 in strain MGB874 (strain 874 $\triangle$ rocG).

Results: Transcriptome analysis and cultivation profiles suggest that this phenomenon is attributable to impaired secretion of alkaline cellulase Egl-237 and nitrogen starvation, caused by decreased external $\mathrm{pH}$ and ammonium depletion, respectively. With $\mathrm{NH}_{3}-\mathrm{pH}$ auxostat fermentation, production of alkaline cellulase Egl-237 in strain $874 \Delta$ rocG was increased, exceeding that in the wild-type-background strain $168 \Delta \mathrm{rocG}$. Notably, in strain $874 \Delta \mathrm{rocG}$, high enzyme productivity was observed throughout cultivation, possibly due to enhancement of metabolic flux from 2-oxoglutarate to glutamate and generation of metabolic energy through activation of the tricarboxylic acid (TCA) cycle. The level of alkaline cellulase Egl-237 obtained corresponded to about $5.5 \mathrm{~g} \mathrm{l}^{-1}$, the highest level reported so far.

Conclusions: We found the highest levels of production of alkaline cellulase Egl-237 with the reduced-genome strain $874 \Delta$ rocG and using the $\mathrm{NH}_{3}-\mathrm{pH}$ auxostat. Deletion of the glutamate dehydrogenase gene rocG enhanced enzyme production via a prolonged auxostat fermentation, possibly due to improved glutamate synthesis and enhanced generation of metabolism energy.
\end{abstract}

Keywords: Bacillus subtilis, Protein secretion, Genome reduction, Glutamate metabolism

\section{Background}

Bacillus subtilis is attractive for industrial use for a variety of reasons, including its rapid growth rate, ability to secrete proteins into the medium, and its 'generally regarded as safe' (GRAS) status [1,2]. B. subtilis is also one of the best-characterized model microorganisms, as

\footnotetext{
* Correspondence: ozaki.katsuya@kao.co.jp; nogasawa@bs.naist.jp

${ }^{\dagger}$ Equal contributors

'Biological Science Laboratories, Kao Corporation, 2606 Akabane, Ichikai, Haga, Tochigi 321-3497, Japan

${ }^{2}$ Graduate School of Biological Science, Nara Institute of Science and

Technology, 8916-5 Takayama, Ikoma, Nara 630-0101, Japan

Full list of author information is available at the end of the article
}

a result of extensive biochemical, genetic, and molecular biological studies $[3,4]$. B. subtilis has been used for the industrial production of enzymes for detergents, foods, and beverages. In industrial-scale production of enzymes, improvement of production levels is a major topic of interest.

We previously reduced the size of the B. subtilis genome by deleting unnecessary regions in order to construct a simplified microbial cell 'factory' for recombinant enzyme production. To do this, we constructed a multiple-deletion mutant strain, MGB874, via the sequential deletion of 865 genes (874 kb; 20.7\%) from B. subtilis strain 168 [5,6]. As

\section{Biomed Central}


compared to strain 168, strain MGB874 shows enhanced production of the exogenous secreted alkaline cellulase Egl-237 [7] and alkaline protease M-protease [8] from plasmid-encoded genes in modified 2xL-Mal medium, a model medium for industrial protein production.

We have also shown that deletion of the rocR gene is an important contributor to the high level of enzyme production that we observe in genome-reduced strain MGB874 [9]. The RocR protein is a positive regulator of genes related to the arginine degradation pathway, including RocG, a major glutamate dehydrogenase [10-13]. RocG has another role as a regulatory protein that inhibits GltC, a transcription activator protein of the glt $A B$ operon, which encodes glutamate synthase [14]. Thus, in strain MGB874, deletion of rocR not only inhibits glutamate degradation pathway but also activates the glutamate synthesis pathway (Figure 1). We proposed that this change of glutamate metabolism in strain MGB874 increases the flux from 2-oxoglutarate to glutamate, which might lead to increased syntheses of the other amino acids via transamination, finally resulting in enhanced enzyme production [9].

Additionally, we found that RocG also serves as an important factor influencing enzyme production by helping to prevent acidification of the growth medium. Decreased expression of $r o c G$ reduces the level of deamination of glutamate, a major cellular ammonia-releasing reaction [15], and leads to a decrease in the external $\mathrm{pH}$

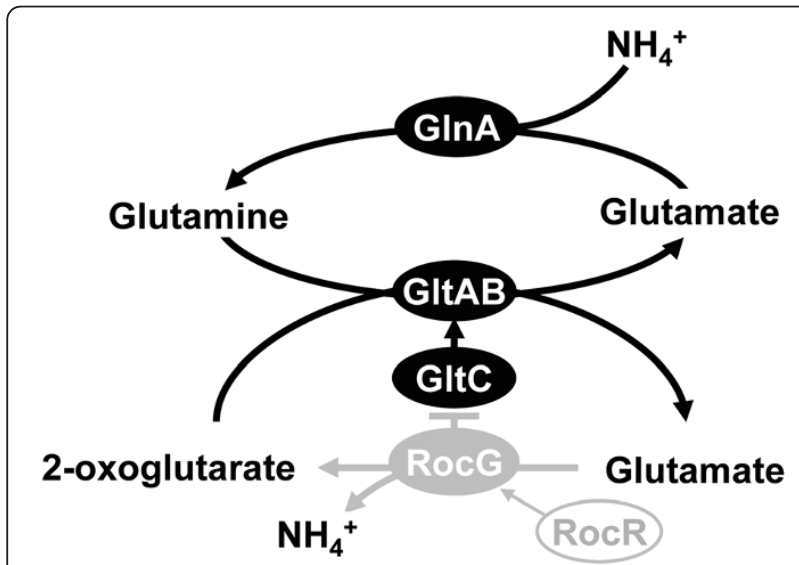

Figure 1 Major reactions and regulation involved in glutamate metabolism in B. subtilis. Proteins are shown as ovals. RocG, glutamate dehydrogenase; GltAB, glutamate synthase (GOGAT); GlnA, glutamine synthetase (GS). In B. subtilis, glutamate can be degraded by RocG. B. subtilis has a glutamine synthetase-glutamate synthase (GS-GOGAT) pathway for assimilation of ammonia. The RocR and GltC transcription factors positively regulate rocG and gltAB, respectively, and GltC can be inhibited via interaction with RocG. Open and closed gray ovals indicate proteins corresponding to genes that have been deleted or inactivated, respectively, in strain MGB874. Deletion of rocR in strain MGB874 decreases expression of rocG, which leads to an increase in expression of glt $A B$ due to activation of GltC via disinhibition by RocG. during strain MGB874 cultivation [16]. We found that the decreased external $\mathrm{pH}$ impaired production of the alkaline $\alpha$-amylase AmyK38, accompanied by the induction of expression of htrA and htrB, which encode serine-type surface proteases and are known to be CssRS dependent [16]. In B. subtilis, the CssRS two-component system responds to the accumulation of misfolded proteins at the membrane-cell wall interface [17]. Alkaline $\alpha$-amylase AmyK38 is thought to fold ineffectively at acidic external $\mathrm{pH}$, leading to secretion stress. Therefore, at least in terms of the production of the alkaline $\alpha$-amylase AmyK38, RocG appears to have a positive role in preventing acidification of the growth medium.

The aim of the present study was to enhance enzyme production in genome-reduced strain MGB874 through further optimization of glutamate metabolism. Belitsky et al. reported that $\operatorname{roc} G$ is still expressed at a low level due to read-through transcription of the upstream gene $y w e A$, even in the absence of the RocR activator sequence [18]. Thus, deletion of $\operatorname{roc} G$ might release repression of gltAB in strain MGB874 completely, further enhancing enzyme production. However, we previously observed that deletion of rocG in strain MGB874 (strain $874 \Delta$ rocG) led to a dramatic decrease in production of the alkaline cellulase Egl-237, even in spite of an observed increase in cell yield [9]. At that time, it remained unclear if this phenomenon is caused by acidification of the growth medium, as in the case of alkaline $\alpha$-amylase production. Here, we investigated the mechanisms underlying decreased enzyme production in strain $874 \Delta$ rocG and attempted to boost production of alkaline cellulase Egl-237 by overcoming the rate-limiting factors we identified.

\section{Results and discussion}

\section{Growth characteristics of strains MGB874 and $874 \Delta$ rocG} producing alkaline cellulase Egl-237

In our recent study, we found that deletion of the rocG gene in the genome-reduced strain MGB874 dramatically decreased the level of production of the alkaline cellulase Egl-237, despite an increase in cell yield [9]. Previous studies showed that mutations in rocG result in the rapid accumulation of suppressor mutations in $\operatorname{gudB}$, a second, cryptic glutamate dehydrogenase gene harboring an insertion of three amino acids with respect to the common ancestral GluDH sequence $[11,19,20]$. However, sequence analysis of $\operatorname{gudB}$ alleles in strains MGB874 and 874 $\triangle$ rocG revealed that the insertion mutation of the three amino acids has been retained in these strains.

To obtain insight into the mechanism responsible for decreased enzyme production in strain $874 \Delta$ rocG, we conducted time course analyses of production of alkaline cellulase Egl-237 in strains MGB874 and 874 $\Delta$ rocG under batch fermentation conditions achieved using a 30-liter jar 
fermentor. As shown in Figure 2A and 2B, after the transition phase, production of alkaline cellulase Egl-237 in strain $874 \Delta$ rocG dramatically decreased as compared with strain MGB874, although the cell yield in strain $874 \Delta$ rocG was higher. Additionally, in the culture medium at the transition phase, we observed a decrease in $\mathrm{pH}$ and ammonium depletion for strain $874 \Delta$ rocG as compared to strain MGB874 during cultivation (Figure 2C and 2D).

\section{Comparison of transcriptome profiles of strains MGB874 and $874 \Delta$ rocG}

We then compared transcriptome profiles of MGB874 and $874 \Delta$ rocG cells at transition phase (at $18 \mathrm{~h}$, indicated by arrow in Figure 2) using a custom Affymetrix tilling chips. The top-ranked 20 up-regulated genes and bottomranked 20 down-regulated genes in $874 \Delta$ rocG cells were listed in Tables 1 and 2, respectively. Firstly, we found that expression of htrA was markedly induced in $874 \Delta$ rocG cells (Table 1). Our previous study revealed that the decrease in external $\mathrm{pH}$ impaired secretion of alkaline $\alpha$ amylase AmyK38 in strain MGB874, and induced htrA and $h \operatorname{tr} B$ expression [16]. Indeed, expression of $h \operatorname{tr} B$ was also induced in $874 \Delta$ rocG cells (4.62 fold) as compared to strain MGB874 cells in our transcriptome analysis. Additionally, time course analysis using qRT-PCR confirm that $h \operatorname{tr} B$ expression is up-regulated in $874 \Delta$ rocG cells during early stationary phase (from 18 to 24 h, Figure 3 ). These results suggest that acidification of the growth medium might impair secretion of alkaline cellulase Egl-237 in $874 \Delta$ rocG cells.

Importantly, we found that many of the genes that are activated or repressed in $874 \Delta$ rocG cells are controlled by the transcriptional factor TnrA. Indeed, 10 of the bottom-ranked 20 genes and 8 of the top-ranked 20 genes were members of the TnrA regulon (Tables 1 and 2). TnrA is a major transcription factor in B. subtilis that controls gene expression under nitrogen-limited growth [23-25]. Time course analysis revealed that $n r g A$, an ammonia transporter gene regulated by TnrA, is transiently up-regulated in $874 \Delta$ rocG cells just before cells enter the stationary phase (at $18 \mathrm{~h}$, Figure 3), which corresponds to the point that ammonium depletion occurs in the culture medium during culture of strain $874 \Delta$ rocG (Figure 2D). These results clearly indicate that nitrogen starvation is induced in $874 \Delta$ rocG cells likely due to ammonium depletion in the culture medium.

Expression of glutamate synthase (GltAB) is also known to be negatively regulated by TnrA [26], in addition to its regulation by GltC. Indeed, expression of glt $A$ in $874 \Delta$ rocG cells significantly decreased after depletion of ammonium to levels lower than that in MGB874 cells, although glt $A$ levels in $874 \Delta$ rocG cells were much higher than levels in MGB874 cells before entering stationary phase (at $18 \mathrm{~h}$, Figure 3). These results indicate that although activation of the glutamate synthetic pathway is induced via deletion of $\operatorname{roc} G$ during the early growth phase as expected, it is subsequently suppressed by depletion of ammonium in the culture medium.

\section{Cultivation using the $\mathrm{NH}_{3}-\mathrm{pH}$ auxostat approach improves enzyme production in strain $874 \Delta$ rocG}

To exclude the influence of decreased $\mathrm{pH}$ and depletion of ammonia in the growth medium associated with culture of strain $874 \Delta$ rocG, we next performed $\mathrm{pH}$-stat fermentation using $\mathrm{NaOH}$ or aqueous $\mathrm{NH}_{3}$ and a 2-L jar fermentor (Figure 4). The $\mathrm{pH}$ of the growth media was adjusted to 7.2, which corresponds to the highest $\mathrm{pH}$ observed in the growth medium of strain MGB874 in the absence of $\mathrm{pH}$ control (Figure 4A). Additionally, to prevent the carbon source from becoming a limiting factor, the initial concentration of maltose in the growth media was increased from $7.5 \%$ to $12.5 \%$, which is sufficient in these fermentation conditions (data not shown).

When fermentation was performed without $\mathrm{pH}$ control, the growth characteristics were similar to the results shown in Figure 2. On the other hand, when $\mathrm{pH}$-stat
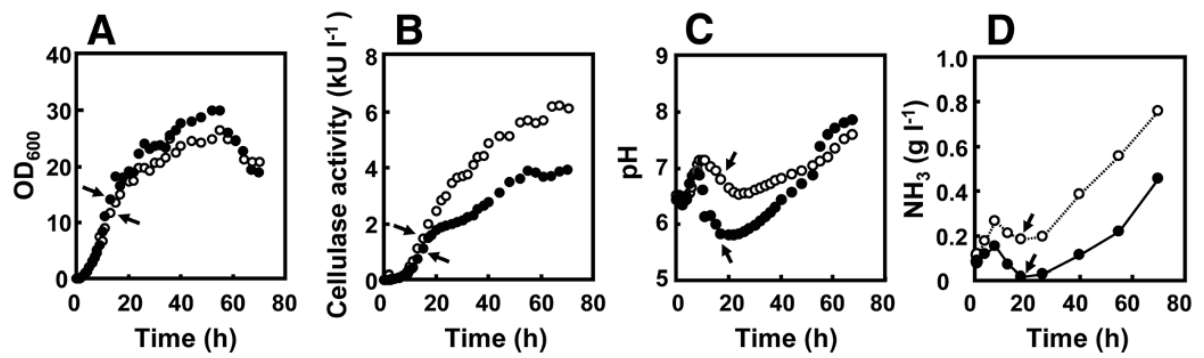

Figure 2 Growth characteristics of strains MGB874 and $874 \Delta$ rocG producing the alkaline cellulase Egl-237. Strains MGB874 (open circles) or MGB874 $\triangle$ rocG (closed circles) were transformed with pHYS237 for production of alkaline cellulase Egl-237. The strains were cultured in $2 \times L$ medium containing $7.5 \%(\mathrm{w} / \mathrm{v})$ maltose monohydrate by batch fermentation with a 30-L jar fermentor. Cell yield (A), extracellular cellulase activity (B), external pH of the growth media (C) and ammonia concentration in the growth media (D) were measured at the indicated times. Arrows indicate the point at which transcriptome analyses were conducted. 
Table 1 Genes up-regulated in 874 $\Delta$ rocG cells (top-ranked 20 genes)

\begin{tabular}{|c|c|c|c|c|c|c|}
\hline \multirow[t]{2}{*}{ Gene $^{a}$} & \multirow[t]{2}{*}{ Product $^{a}$} & \multirow[t]{2}{*}{ Function $^{a}$} & \multicolumn{2}{|c|}{ Average signal $^{\mathbf{b}}$} & \multirow[t]{2}{*}{ Ratio $^{c}$} & \multirow{2}{*}{$\begin{array}{l}\text { Transcriptional } \\
\text { factor }^{\mathrm{d}}\end{array}$} \\
\hline & & & MGB874 & $874 \Delta$ rocG & & \\
\hline$n r g A$ & ammonium transporter & ammonium uptake & 208 & 3926 & 18.91 & $\operatorname{Tn} \mathrm{A}(+)$ \\
\hline$y v r l$ & co-sigma factor with YvrHa & RNA polymerase sigma factor & 92 & 1266 & 13.78 & $\mathrm{YvrH}(+)$ \\
\hline$y k z B$ & unknown & unknown & 92 & 1078 & 11.72 & $\operatorname{TnrA}(+)$ \\
\hline nasC & nitrate reductase (catalytic subunit) & utilization of nitrate & 128 & 1463 & 11.46 & $\mathrm{G} \ln R(-), \operatorname{Tn} \mathbf{A}(+)$ \\
\hline ans $Z$ & asparaginase & asparagine utilization & 202 & 1976 & 9.78 & $\operatorname{Tn} \mathrm{A}(+)$ \\
\hline $\operatorname{tnr} A$ & transcription activator/ repressor & regulation of nitrogen assimilation & 103 & 981 & 9.56 & $\operatorname{Tn} A(+)$ \\
\hline nas $A$ & nitrate transporter & nitrate uptake & 227 & 1975 & 8.7 & $\mathrm{G} \ln R(-), \operatorname{Tn} \mathbf{A}(+)$ \\
\hline$y v m B$ & unknown & unknown & 119 & 977 & 8.23 & \\
\hline yjgD & unknown & survival of ethanol stress & 158 & 1185 & 7.51 & \\
\hline nas $B$ & nitrate reductase (electron transfer subunit) & utilization of nitrate & 180 & 1346 & 7.49 & $\mathrm{G} \ln R(-), \operatorname{Tn} \mathbf{A}(+)$ \\
\hline htrA & serine protease Do & protein quality control & 719 & 4742 & 6.6 & $\operatorname{CssR}(+), \operatorname{Htr} A(-)$ \\
\hline$y g \times B$ & unknown & unknown & 184 & 1156 & 6.29 & \\
\hline$y q z H$ & unknown & unknown & 248 & 1463 & 5.9 & $\operatorname{LexA}(-)$ \\
\hline spoVFB & dipicolinate synthase (subunit B) & dipicolic acid production & 82 & 475 & 5.8 & \\
\hline $\operatorname{nrg} B$ & nitrogen-regulated PII-like protein & regulation of ammonium uptake & 821 & 4727 & 5.76 & $\operatorname{Tn} r A(+)$ \\
\hline$n t d A$ & sugar aminotransferase & $\begin{array}{l}\text { synthesis of antibiotic } \\
\text { neotrehalosadiamine }\end{array}$ & 133 & 707 & 5.33 & YhjM(+) \\
\hline$b m r U$ & multidrug resistance protein & multidrug resistance & 180 & 949 & 5.28 & \\
\hline$y r b D$ & $\begin{array}{l}\text { sodium/proton-dependent alanine } \\
\text { transporter }\end{array}$ & uptake of alanine & 327 & 1721 & 5.27 & \\
\hline yit & unknown & unknown & 247 & 1301 & 5.26 & \\
\hline yuzA & unknown & unknown & 146 & 758 & 5.2 & \\
\hline
\end{tabular}

${ }^{\mathrm{a}}$ The SubtiWiki was used as a reference for the genes, products and functions [21].

${ }^{\mathrm{b}}$ The average signal intensities of probes in each coding sequence.

'The ratio of each of the genes was obtained by dividing the average signal intensity in each coding sequence of $874 \Delta$ rocG cells by that for MGB874 cells.

${ }^{\mathrm{d}}$ The Database of Transcriptional Regulation in Bacillus subtilis (DBTBS) was used as a reference [22]. Transcriptional activators or repressors are indicated by a (+) or (-), respectively. TnrA is shown in bold type.

fermentation using $\mathrm{NaOH}$ was performed, the production of alkaline cellulase Egl-237 in strain $874 \Delta$ rocG was improved to nearly the same level as that observed for strain MGB874 (Figure 4B). In both these cases, the concentrations of ammonia were significantly decreased as compared to those reached during cultivation without $\mathrm{pH}$ control. To examine if the decrease in ammonia affects production of alkaline cellulase Egl-237, we performed $\mathrm{pH}$-stat fermentation using aqueous $\mathrm{NH}_{3}$, using a so-called $\mathrm{NH}_{3}-\mathrm{pH}$ auxostat [27] (Figure 4C). The enzyme production period in strain $874 \Delta$ rocG was prolonged with use of the $\mathrm{NH}_{3}-\mathrm{pH}$ auxostat, whereas the production profile of alkaline cellulase Egl-237 in MGB874 cells was similar in both cultivation conditions. With the $\mathrm{NH}_{3}-\mathrm{pH}$ auxostat, the production of alkaline cellulase Egl-237 in strain $874 \Delta$ rocG was 1.67 -fold higher than that in strain MGB874 at the end of the cultivation period (Figure 4C). Production of alkaline cellulase Egl-237 in strain $874 \Delta$ rocG corresponded to about $5.5 \mathrm{~g} \mathrm{l}^{-1}$, the highest level reported so far [6].
Notably, the level of residual ammonia in the growth medium from strain $874 \Delta$ rocG was lower than that from strain MGB874, although the total amount of ammonia introduced into the growth medium for strain $874 \Delta$ rocG was considerably larger than that for strain MGB874 (Figure 4C). These data suggest that the ratio of assimilated ammonia in $874 \Delta$ rocG cells was higher than that in MGB874 cells and furthermore, that assimilation activity is maintained through late stages of cultivation.

It should be noted that the $\operatorname{roc} G$ deletion in wild-type

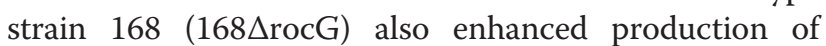
alkaline cellulase Egl-237 with the $\mathrm{NH}_{3}-\mathrm{pH}$ auxostat (Additional file 1: figure S1). In this experiment, we also confirmed that the insertion mutation of the three amino acids was retained in strain $168 \Delta$ rocG. Notably, the production level from strain $168 \Delta$ rocG $\left(2.8 \mathrm{~g} \mathrm{l}^{-1}\right)$ was about half of that of strain $874 \Delta$ rocG, indicating the importance of the genetic background of the reducedgenome strain for higher levels of alkaline cellulase Egl-237 production. 
Table 2 Genes down-regulated in $874 \Delta$ rocG cells (bottom-ranked 20 genes)

\begin{tabular}{|c|c|c|c|c|c|c|}
\hline \multirow[t]{2}{*}{ Gene $^{a}$} & \multirow[t]{2}{*}{ Product $^{\mathrm{a}}$} & \multirow[t]{2}{*}{ Function $^{a}$} & \multicolumn{2}{|c|}{ Average signal $^{\mathbf{b}}$} & \multirow[t]{2}{*}{ Ratio $^{c}$} & \multirow[t]{2}{*}{ Transcriptional factor ${ }^{\mathrm{c}}$} \\
\hline & & & MGB874 & $874 \Delta$ rocG & & \\
\hline yuiA & unknown & unknown & 4307 & 533 & 0.12 & \\
\hline yycC & unknown & unknown & 1915 & 273 & 0.14 & $\operatorname{Tn} A(-)$ \\
\hline$y y c B$ & unknown & unknown & 1883 & 287 & 0.15 & $\operatorname{TnrA}(-)$ \\
\hline$d h b C$ & isochorismate synthase & $\begin{array}{l}\text { biosynthesis of the } \\
\text { siderophore bacillibactin }\end{array}$ & 2560 & 529 & 0.21 & Fur(-) \\
\hline pel & pectate lyase $C$ & $\begin{array}{l}\text { degradation of } \\
\text { polygalacturonic acid }\end{array}$ & 3736 & 808 & 0.22 & $\operatorname{ComA}(+), \operatorname{Tn} \mathbf{A}(-)$ \\
\hline$i / v B$ & acetolactate synthase (large subunit) & $\begin{array}{l}\text { biosynthesis of branched- } \\
\text { chain amino acids }\end{array}$ & 2106 & 459 & 0.22 & $\begin{array}{l}\operatorname{CcpA}(+), \operatorname{CodY}(-), \operatorname{TnrA} \\
(-), \operatorname{TrnS}-\operatorname{Leu} 2(+)\end{array}$ \\
\hline leuB & 3-isopropylmalate dehydrogenase & biosynthesis of leucine & 2072 & 467 & 0.23 & $\begin{array}{l}\operatorname{CcpA}(+), \operatorname{CodY}(-), \operatorname{Tnr} A \\
(-), \operatorname{TrnS}-\operatorname{Leu} 2(+)\end{array}$ \\
\hline$d h b F$ & unknown & $\begin{array}{l}\text { biosynthesis of the } \\
\text { siderophore bacillibactin }\end{array}$ & 2081 & 474 & 0.23 & Fur(-) \\
\hline $\operatorname{ser} A$ & phosphoglycerate dehydrogenase & biosynthesis of serine & 2575 & 603 & 0.23 & \\
\hline leuA & 2-isopropylmalate synthase & biosynthesis of leucine & 1680 & 396 & 0.24 & $\begin{array}{l}\operatorname{CcpA}(+), \operatorname{CodY}(-), \operatorname{TnrA} \\
(-), \operatorname{TrnS}-\operatorname{Leu} 2(+)\end{array}$ \\
\hline$d h b B$ & isochorismatase & $\begin{array}{l}\text { biosynthesis of the } \\
\text { siderophore bacillibactin }\end{array}$ & 1897 & 447 & 0.24 & Fur $(-)$ \\
\hline leuc & 3-isopropylmalate dehydratase (large subunit) & biosynthesis of leucine & 2166 & 516 & 0.24 & $\begin{array}{l}\operatorname{CcpA}(+), \operatorname{CodY}(-), \operatorname{Tnr} A \\
(-), \operatorname{TrnS}-\operatorname{Leu} 2(+)\end{array}$ \\
\hline$i l v C$ & $\begin{array}{l}\text { ketol-acid reductoisomerase (2,3-dihydroxy-3- } \\
\text { methylbutanoate, 2-acetolactate) }\end{array}$ & $\begin{array}{l}\text { biosynthesis of branched- } \\
\text { chain amino acids }\end{array}$ & 2981 & 713 & 0.24 & $\begin{array}{l}\operatorname{CcpA}(+), \operatorname{CodY}(-), \operatorname{Tnr} A \\
(-), \operatorname{TrnS}-\operatorname{Leu} 2(+)\end{array}$ \\
\hline yocs & putative sodium-dependent transporter & unknown & 1028 & 248 & 0.24 & \\
\hline yodF & unknown & unknown & 737 & 182 & 0.25 & $\operatorname{TnrA}(-)$ \\
\hline$y d z A$ & unknown & unknown & 1035 & 266 & 0.26 & \\
\hline$y x \times G$ & unknown & unknown & 435 & 119 & 0.27 & $\operatorname{DegU}(-), \mathrm{YvrH}(+)$ \\
\hline$d h b E$ & $\begin{array}{l}\text { 2,3-dihydroxybenzoate-AMP ligase (enterobactin } \\
\text { synthetase component E }\end{array}$ & $\begin{array}{l}\text { biosynthesis of the } \\
\text { siderophore bacillibactin }\end{array}$ & 1539 & 439 & 0.29 & Fur(-) \\
\hline leud & 3-isopropylmalate dehydratase (small subunit) & biosynthesis of leucine & 1137 & 327 & 0.29 & $\begin{array}{l}\operatorname{CcpA}(+), \operatorname{CodY}(-), \operatorname{Tnr} A \\
(-), \operatorname{TrnS}-\operatorname{Leu} 2(+)\end{array}$ \\
\hline yuiB & unknown & unknown & 3785 & 1150 & 0.3 & \\
\hline
\end{tabular}

${ }^{\mathrm{a}}$ The SubtiWiki was used as a reference for the genes, products and functions [21].

${ }^{\mathrm{b}}$ The average signal intensities of probes in each coding sequence.

'The ratio of each of the genes was obtained by dividing the average signal intensity in each coding sequence of $874 \Delta$ rocG cells by that for MGB874 cells.

${ }^{\mathrm{d}}$ The Database of Transcriptional Regulation in Bacillus subtilis (DBTBS) was used as a reference [22]. Transcriptional activators or repressors are indicated by a (+) or (-), respectively. TnrA is shown in bold type.
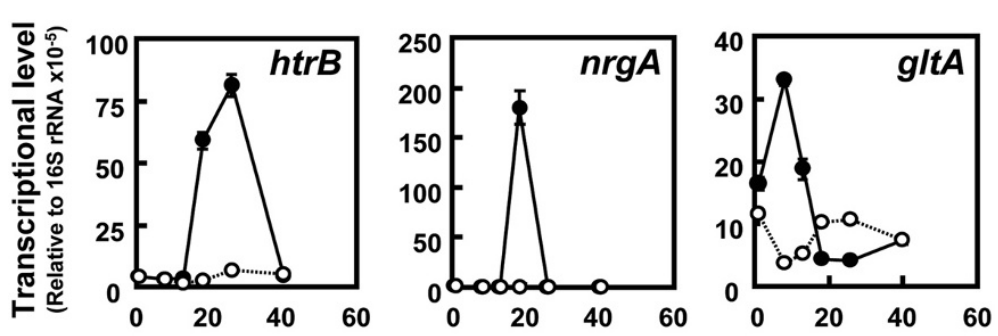

Time (h)

Figure 3 Time course of transcription during growth of $B$. subtilis strains MGB874 and $874 \Delta$ rocG. The strains MGB874 (open circles) and $874 \triangle$ rocG (closed circles) were transformed with pHYS237. The transformants were cultured using shake-flask fermentation. Transcript levels for htrB, $\operatorname{nrg} A$ and gltA were determined by qRT-PCR (primers shown in Additional file 2: Table S1). Transcript levels were normalized to 165 rRNA levels. Error bars represent standard deviations $(n=3)$. 


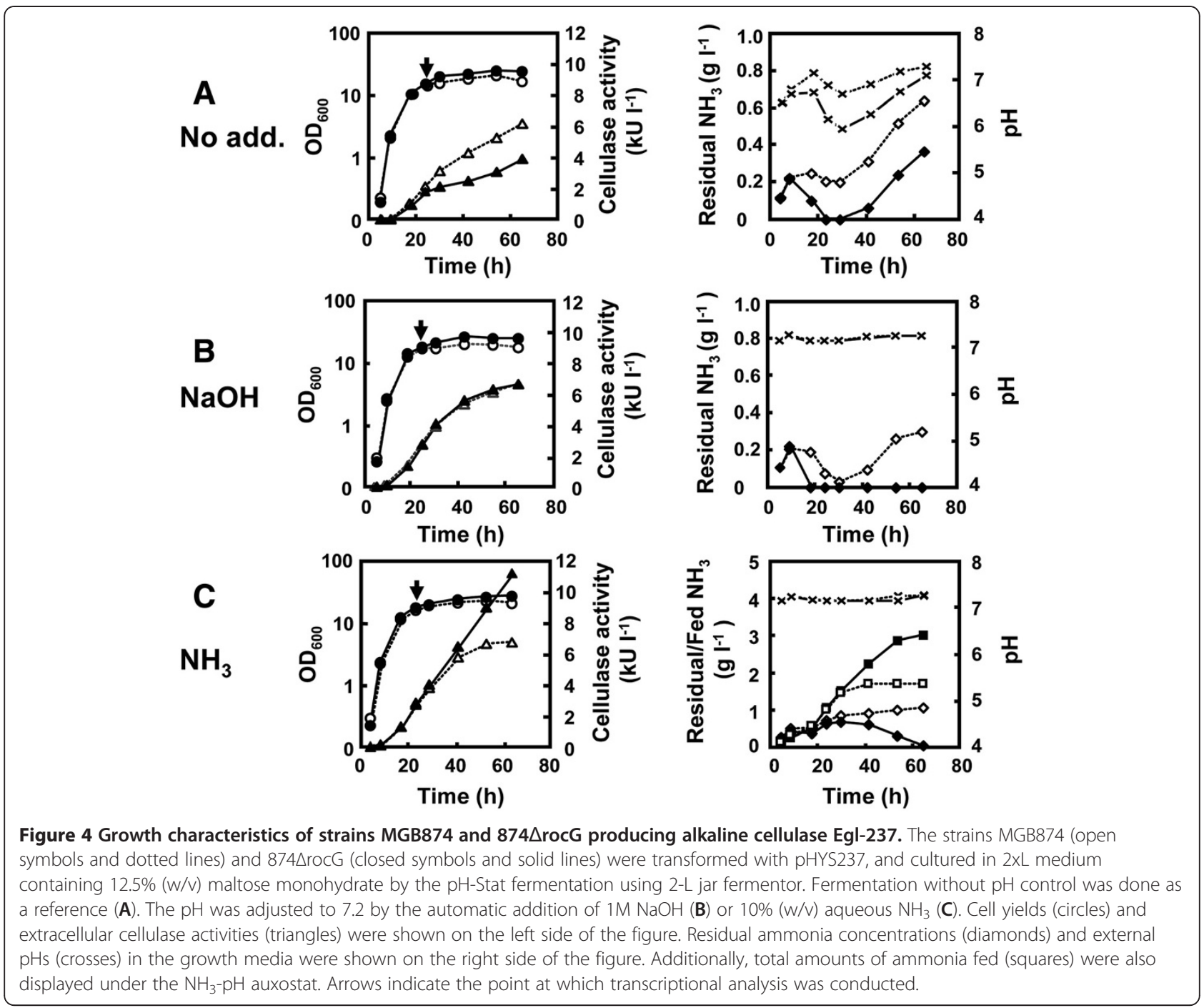

Changes in gene expression underlying improvement in enzyme production with $\mathrm{pH}$-stat fermentation

To investigate the changes in gene expression underlying the improvement of enzyme production in $874 \Delta$ rocG cells under $\mathrm{pH}$-stat fermentation, RNA was extracted from cells at $24 \mathrm{~h}$ of cultivation (Figure 4; arrows), and expression levels of selected genes were measured by qRT-PCR (Figure 5). Although transcriptional levels for selected genes were not significantly changed in MGB874 cells under any fermentation conditions, remarkable changes in expression of these genes were observed in $874 \Delta$ rocG.

Firstly, expression of $h t r B$ was reduced to the same level in strain MGB874 under fermentation conditions with $\mathrm{pH}$-control not only with aqueous $\mathrm{NH}_{3}$ but also with $\mathrm{NaOH}$, clearly indicating that the CssRS-dependent secretion stress response is induced by overproduction of alkaline cellulase Egl-237 in $874 \Delta$ rocG cells under the low external $\mathrm{pH}$ condition (Figure 5). Notably, production of alkaline cellulase Egl-237 did not induce the secretion stress response in MGB874 cells (Figures 3 and 5) but overproduction of alkaline $\alpha$-amylase AmyK38 induced this response to a high degree in MGB874 cells [16]. Because the decrease of external $\mathrm{pH}$ was more severe in $874 \Delta$ rocG cultivation (without $\mathrm{pH}$ control) compared to that in MGB874 cultivation (Figure 4A), the threshold value of external $\mathrm{pH}$ leading to secretion stress responses for overproduction of alkaline cellulase Egl-237 would be lower than for the overproduction of AmyK38.

We also found that expression of $\operatorname{nrgA}$, known to be activated under nitrogen-limited growth, was downregulated in $874 \Delta$ rocG cells using the $\mathrm{NH}_{3}-\mathrm{pH}$ auxostat, suggesting avoidance of nitrogen starvation (Figure 5). Furthermore, the expression level of gltA, encoding a subunit of glutamate synthase, was 9-fold higher in $874 \Delta$ rocG cells than in MGB874 when using the $\mathrm{NH}_{3}$ - 


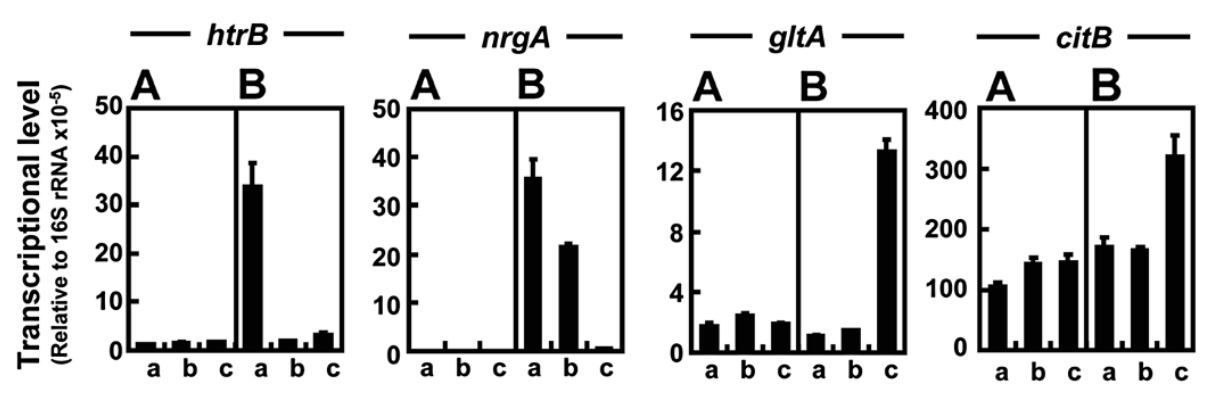

Figure $\mathbf{5}$ Transcriptional levels of selected genes in strains MGB874 and $\mathbf{8 7 4} \Delta$ rocG. The strains $M G B 874$ (A) and $874 \triangle$ rocG (B) were transformed with pHYS237, and cultured by the $\mathrm{pH}$-Stat fermentation. Fermentation without pH control was done as a reference (a). The pH was adjusted to 7.2 by addition of $\mathrm{NaOH}$ (b) or aqueous $\mathrm{NH}_{3}$ (c). RNA was isolated from the cells at the $24 \mathrm{~h}$ of the cultivation time (indicated by arrows in Figure 4), and expression level of $h \operatorname{tr} B, n r g A, g l t A$ and citB were determined by qRT-PCR. The transcriptional levels are expressed relative to those of $16 \mathrm{~S}$ rRNA. Error bars represent standard deviations $(n=3)$.

$\mathrm{pH}$ auxostat (Figure 5). As ammonia can be assimilated via the glutamine synthetase-glutamate synthase (GS-GOGAT) pathway in B. subtilis (Figure 1), activation of the glutamate synthetic pathway might indirectly contribute to the enhancement of ammonia assimilation ability in $874 \Delta \mathrm{rocG}$ cells (Figure $4 \mathrm{C}$ and 5). With the $\mathrm{NH}_{3}-\mathrm{pH}$ auxostat, the continuous conversion of ammonia to glutamate in $874 \Delta$ rocG cells might lead to increased flux in the synthesis of other amino acids via transamination, resulting in enhanced production of alkaline cellulase Egl-237.

As mentioned, enzyme productivity lasted through the end of the cultivation period in strain $874 \Delta$ rocG with use of the $\mathrm{NH}_{3}-\mathrm{pH}$ auxostat but this was not observed for strain MGB874 under the same conditions (Figure 4C). Activation of the glutamate synthetic pathway in $874 \Delta$ rocG cells could account for this difference. Furthermore, we found that expression of the gene encoding aconitase (citB) was up-regulated in $874 \Delta$ rocG cells but not MGB874 cells under $\mathrm{NH}_{3}-\mathrm{pH}$ auxostat (Figure 5). Expression of citB has been reported to be indirectly repressed by 2-oxoglutarate, which competitively represses the reaction of citrate synthase (CitZ), leading to repression of $c i t B$ by the transcriptional regulator $\mathrm{CcpC}$ in the absence of the effector citrate $[28,29]$. Therefore, improvement of metabolic flux from 2-oxoglutarate to glutamate in strain 874 $\Delta$ rocG might lead to activation of $c i t B$ due to inactivation of the repressor CcpC. Blencke et al. reported that TnrA exerts a weak activating effect on citB expression [30]. However, in our experiment, the expression levels of TnrA regulated gene $n r g A$ were almost the same in strains MGB874 and $874 \Delta$ rocG under $\mathrm{NH}_{3}-\mathrm{pH}$ auxostat (Figure 5). Thus, it seems that TnrA did not participate in activation of $c i t B$ in strain $874 \Delta$ rocG, compared to that of strain MGB874 under $\mathrm{NH}_{3}-\mathrm{pH}$ auxostat. Activation of citB might contribute to prolonged high enzyme productivity through the generation of reducing power via the tricarboxylic acid (TCA) cycle.

\section{Conclusion}

Here, we describe conditions resulting in the highest levels of production of alkaline cellulase Egl-237 in $B$. subtilis cells reported to date. We found that deletion of the glutamate dehydrogenase gene rocG in the genomereduced strain MGB874 (874 $\Delta$ rocG) and cultivation of $874 \Delta$ rocG using $\mathrm{NH}_{3}-\mathrm{pH}$ auxostat conditions leads to enhanced enzyme production through prolonged high enzyme productivity until the end of cultivation. This beneficial effect is very likely a consequence of an enhanced metabolic flux from 2-oxoglutarate to glutamate and generation of metabolic energy through activation of the TCA cycle.

Additionally, we found that the overproduction of alkaline cellulase Egl-237 causes the induction of CssRSdependent secretion stress responses in the acidified growth medium below the threshold $\mathrm{pH}$ value, which is lower than that for the overproduction of alkaline $\alpha$ amylase AmyK38.

With the $\mathrm{NH}_{3}-\mathrm{pH}$ auxostat, levels of alkaline cellulase Egl-237 produced by strain $874 \Delta$ rocG far exceeded those produced by the wild-type genetic-background strain $168 \Delta$ rocG, and reached the highest level reported so far, corresponding to $5.5 \mathrm{~g} / \mathrm{L}$. However, it is not clear at the moment if these improvements are attributable to a global synergistic effect of large-scale genome reduction or to individual effects of one or more specific gene deletions. To further improve enzyme production, we are presently attempting to elucidate the mechanisms underlying the improvement in productivity we have observed.

\section{Materials and methods}

Bacterial strains, plasmids, and growth media

The bacterial strains and plasmids used in this study are listed in Table 3. E. coli HB101 (Takara Bio Inc.) was used as the host for plasmid preparation and was grown 
Table 3 Bacterial strains and plasmids used in or constructed for this study

\begin{tabular}{|c|c|c|}
\hline $\begin{array}{l}\text { Strain or } \\
\text { plasmid }\end{array}$ & Relevant properties $^{\dagger}$ & $\begin{array}{l}\text { Source or } \\
\text { reference }\end{array}$ \\
\hline \multicolumn{3}{|l|}{ Strain } \\
\hline \multicolumn{3}{|c|}{ Bacillus subtilis } \\
\hline 168 & $\operatorname{trp} C 2$ & [4] \\
\hline $168 \Delta$ rocG & $\operatorname{trpC2} \Delta$ rocG::spec & This study \\
\hline MGB874 & 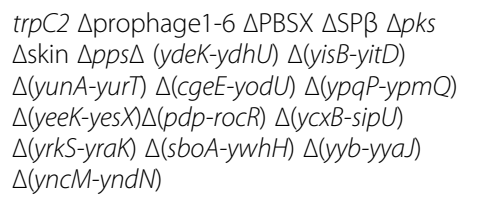 & [6] \\
\hline $874 \Delta$ rocG & MGB874 $\Delta$ rocG::spec & [9] \\
\hline \multicolumn{3}{|c|}{ Escherichia coli } \\
\hline HB101 & $\begin{array}{l}\text { supE44 } \triangle(m c r C-m r r) \text { recA13 ara-14 proA2 } \\
\text { lacY1 galK2 rpsL20 xyl-5 mtl-1 leuB6 thi-1 }\end{array}$ & Takara Bio \\
\hline \multicolumn{3}{|l|}{ Plasmid } \\
\hline pHY300PLK & Shuttle vector for E. coli and B. subtilis & Takara Bio \\
\hline pHYS237 & $\begin{array}{l}\text { pHY300PLK carrying the gene for alkaline } \\
\text { endo-1,4- } \beta \text {-glucanase (Egl-237) from } \\
\text { Bacillus sp. strain KSM-S237, containing } \\
\text { amp and tet }\end{array}$ & [6] \\
\hline
\end{tabular}

${ }^{\dagger}$ Antibiotic resistance genes are abbreviated as follows: amp, ampicillin; tet, tetracycline; spec, spectinomycin; neo, neomycin.

in Luria-Bertani (LB) medium [1\% (w/v) Bacto tryptone (Difco), $0.5 \%$ (w/v) Bacto yeast extract (Difco), and 1\% $(\mathrm{w} / \mathrm{v}) \mathrm{NaCl}$. Strain $168 \Delta \mathrm{rocG}$, a rocG mutant strain derived from strain 168 , was constructed in a similar way to construction of strain $874 \Delta$ rocG, which was described previously [9]. B. subtilis mutant strains were transformed with the plasmid pHYS237 for production of alkaline cellulase Egl-237, which originated from Bacillus sp. strain KSM-S237 [9], using the protoplast transformation method [31]. For enzyme production, we used 2xL medium [2\% (w/v) Bacto tryptone, 1\% (w/v) Bacto yeast extract, 1\% (w/v) $\mathrm{NaCl}, 7.5 \mu \mathrm{g} \mathrm{ml}{ }^{-1}$ manganese sulfate 4-5 hydrate, and $15 \mu \mathrm{g} \mathrm{ml}^{-1}$ Tet] supplemented with $7.5 \%(\mathrm{w} / \mathrm{v})$ or $12.5 \%(\mathrm{w} / \mathrm{v})$ maltose monohydrate.

\section{Culture methods for the assessment of alkaline cellulase Egl-237 production}

For shake-flask fermentation, transformants were precultured in LB medium with $15 \mu \mathrm{g} \mathrm{ml}^{-1}$ Tet with shaking at $120 \mathrm{rpm}$ at $30^{\circ} \mathrm{C}$ for $15 \mathrm{~h}$, and $600 \mu \mathrm{l}$ of the pre-culture was inoculated into $30 \mathrm{ml}$ of $2 \times \mathrm{L}$ medium with $7.5 \%(\mathrm{w} / \mathrm{v})$ maltose monohydrate in a 500-ml Sakaguchi flask.

For jar fermentation, B. subtilis harboring pHYS237 stored in $10 \%$ glycerol at $-80^{\circ} \mathrm{C}$ were inoculated onto LB agar medium with $15 \mu \mathrm{g} \mathrm{ml}{ }^{-1}$ Tet. After incubation at $37^{\circ} \mathrm{C}$ for $12 \mathrm{~h}$, cells were collected and inoculated into pre-culture medium at an optical density at $600 \mathrm{~nm}$
$\left(\mathrm{OD}_{600}\right)$ of 0.02 . For batch fermentation, cells were precultured in $200 \mathrm{ml}$ of $2 \times \mathrm{L}$ medium with $7.5 \%(\mathrm{w} / \mathrm{v})$ maltose monohydrate with shaking at $210 \mathrm{rpm}$ at $30^{\circ} \mathrm{C}$ to an $\mathrm{OD}_{600}$ of 0.3 to 0.5 , then inoculated into a $30-\mathrm{L}$ jar fermentor (working volume, 18 liters). The 30-L jar fermentor was operated at an aeration rate of $0.4 \mathrm{vvm}$ and an agitation rate of $300 \mathrm{rpm}$. For $\mathrm{pH}$-stat fermentation, cells were pre-cultured in $30 \mathrm{ml}$ of $2 \times \mathrm{L}$ medium with $12.5 \%(\mathrm{w} / \mathrm{v})$ maltose monohydrate with shaking at 120 $\mathrm{rpm}$ at $30^{\circ} \mathrm{C}$ to an $\mathrm{OD}_{600}$ of 0.3 to 0.5 , then inoculated into a 2-L jar fermentor (working volume, 0.8 liters). The 2-L jar fermentor was operated at an aeration rate of $0.5 \mathrm{vvm}$ and an agitation rate of $800 \mathrm{rpm}$. The $\mathrm{pH}$ was kept at 7.2 via automatic addition of $1 \mathrm{M} \mathrm{NaOH}$ or $10 \%(w / v)$ aqueous $\mathrm{NH}_{3}$. Fermentation without $\mathrm{pH}$ adjustments was used as a control. As appropriate to specific assays, cultured cells were removed by centrifugation at 9,000 $\times g$ and the supernatants were stored at $-30^{\circ} \mathrm{C}$. For RNA extraction, cells were separated by centrifugation, washed with $10 \mathrm{mM}$ Tris- $\mathrm{HCl}$ ( $\mathrm{pH} 7.5$ ), frozen with liquid nitrogen, and stored at $-80^{\circ} \mathrm{C}$.

\section{Analytical methods and cellulase activity}

The concentration of ammonia and maltose in the culture supernatants was determined by enzymatic analysis according to the F-Kit UV method (Boehringer GmbH). Cellulase activity in the culture medium was determined as described previously [9]. The amount of enzyme required for release of $1 \mu \mathrm{mol}$ of $p$-nitrophenol per minute was defined as $1 \mathrm{U}$.

\section{High-resolution transcriptome analysis}

Total RNA was extracted from B. subtilis cells as described previously [32]. Synthesis of cDNA, terminal labeling, and oligonucleotide chip hybridization were performed as described in the Affymetrix instruction manual. Transcriptional signals were analyzed and visualized along genome coordinates using the program IMC Array Edition (In Silico Biology, Japan). The signal intensities of each experiment were adjusted to confer a signal average of 500 and normalized by MA plot analysis for comparison of strains MGB874 and 874 $\Delta$ rocG. $[33,34]$. The average signal intensities of probes in each coding sequence were calculated after removal of the lowest and highest intensities.

\section{Quantitative real-time PCR}

Quantitative real-time PCR (qRT-PCR) amplification, detection, and analysis were performed with the Mx3005P Real-time PCR system (Stratagene) and Brilliant II Fast SYBR Green QPCR Master Mix (Stratagene), as previously described [9]. The sequences of the primers used in real-time PCR were developed with Primer 3 (version 
0.4.0) [35] and are listed in Additional file 2: Table S1 in the supplemental material. Experimental RNA levels were normalized to $16 \mathrm{~S}$ rRNA levels, as previously described [16].

\section{Additional files}

Additional file 1: Figure S1. Cell yield and alkaline cellulase Egl-237 production under the $\mathrm{NH}_{3}-\mathrm{pH}$ auxostat, The alkaline cellulase Egl-237 overproducing strains in the presence (+) or absence (-) of rocG were cultured by the pH-Stat fermentation. The $\mathrm{pH}$ was adjusted to 7.2 by addition aqueous $\mathrm{NH}_{3}$. The cell yields (at $42 \mathrm{~h}$; open circles) and the cellulase activities in growth media (72h; black bars) were measured. (A) The wild-type strain 168 and strain 168هrocG. (B) The genome-reduced strain MGB874 and strain 874ArocG.

Additional file 2: Table S1. Oligonucleotide primers used for real-time PCR analysis.

\section{Abbreviations}

GRAS: generally regarded as safe; CssRS: Control secretion stress Regulator and Sensor; qRT-PCR: quantitative real-time PCR; NaCl: sodium chloride; Tet: tetracycline.

\section{Competing interests}

The content of this manuscript is relevant to a patent application made by Kao Corporation (Patent no. JP2007-330255A); however, all authors declare that they have no competing interests.

\section{Authors' contributions}

$\mathrm{NO}, \mathrm{KO}$, and $\mathrm{KA}$ initiated and coordinated the project. KM and YK drafted the manuscript, constructed mutant strains, evaluated production levels of alkaline cellulase Egl-237, and measured $\mathrm{pH}$ and ammonium concentrations in the growth medium. KM and TM performed tilling array and GPCR. ES supported our results by metabolic analysis. HT and SK processed tilling array data. NO and KO supervised the study and reviewed results. All authors have read and approved the final manuscript.

\section{Acknowledgements}

We thank Junichi Sekiguchi (Shinshu University), Kouji Nakamura (University of Tsukuba), Shu Ishikawa (Nara Institute of Science and Technology), Fujio Kawamura (University of Rikkyo), and Yasutaro Fujita (Fukuyama University) for valuable discussions. We also thank Yoshiharu Kimura and Yoshinori Takema (Kao Corp.) for valuable advice. This study was performed in collaboration with Shengao Liu (Kao Corp.), Takeko Kodama (Kao Corp.), Hiroshi Kakeshita (Kao Corp.), Tadahiro Ozawa (Kao Corp.), Hiroshi Kodama (Kao Corp.), Kazuhiro Saito (Kao Corp.), Akihito Kawahara (Kao Corp.) and Nozomu Shibata (Kao Corp.). This research was conducted as part of the Project for the Development of a Technological Infrastructure for Industrial Bioprocesses through R\&D on New Industrial Science and Technology Frontiers of the Ministry of Economy, Trade, and Industry (METI), Japan, and was supported by the New Energy and Industrial Technology Development Organization (NEDO), Japan.

\section{Author details}

'Biological Science Laboratories, Kao Corporation, 2606 Akabane, Ichikai, Haga, Tochigi 321-3497, Japan. ${ }^{2}$ Graduate School of Biological Science, Nara Institute of Science and Technology, 8916-5 Takayama, Ikoma, Nara 630-0101, Japan. ${ }^{3}$ Analytical Science Laboratories, Kao Corporation, 2606 Akabane, Ichikai, Haga, Tochigi 321-3497, Japan. ${ }^{4}$ Medical Mycology Research Center, Chiba University, 1-8-1 Inohana, Chuo-ku, Chiba 260-8673, Japan. ${ }^{5}$ Graduate School of Information Science, Nara Institute of Science and Technology, 8916-5 Takayama, Ikoma, Nara 630-0101, Japan. 6Fundamental Technology Research Laboratories, Kao Corporation, 623 Zi Ri Rd, Minhang Dist, Shanghai 200241, China.

Received: 9 December 2012 Accepted: 6 February 2013

Published: 18 February 2013

\section{References}

1. Schallmey M, Singh A, Ward OP: Developments in the use of Bacillus species for industrial production. Can J Microbiol 2004, 50:1-17.

2. Simonen M, Palva I: Protein secretion in Bacillus species. Microbiol Rev 1993, 57:109-137.

3. Barbe V, Cruveiller S, Kunst F, Lenoble P, Meurice G, Sekowska A, Vallenet D, Wang T, Moszer I, Medigue $C$, et al: From a consortium sequence to a unified sequence: the Bacillus subtilis 168 reference genome a decade later. Microbiology 2009, 155:1758-1775.

4. Kunst F, Ogasawara N, Moszer I, Albertini AM, Alloni G, Azevedo V, Bertero MG, Bessieres P, Bolotin A, Borchert S, et al: The complete genome sequence of the gram-positive bacterium Bacillus subtilis. Nature 1997 390:249-256.

5. Ara K, Ozaki K, Nakamura K, Yamane K, Sekiguchi J, Ogasawara N: Bacillus minimum genome factory: effective utilization of microbial genome information. Biotechnol Appl Biochem 2007, 46(Pt 3):169-178.

6. Morimoto T, Kadoya R, Endo K, Tohata M, Sawada K, Liu S, Ozawa T, Kodama T, Kakeshita $H$, Kageyama $Y$, et al: Enhanced recombinant protein productivity by genome reduction in Bacillus subtilis. DNA Res 2008, 15:73-81.

7. Hakamada Y, Hatada Y, Koike K, Yoshimatsu T, Kawai S, Kobayashi T, Ito S: Deduced amino acid sequence and possible catalytic residues of a thermostable, alkaline cellulase from an alkaliphilic Bacillus strain. Biosci Biotechnol Biochem 2000, 64:2281-2289.

8. Kobayashi T, Hakamada Y, Adachi S, Hitomi J, Yoshimatsu T, Koike K, Kawai S, Ito $S$ : Purification and properties of an alkaline protease from alkalophilic Bacillus sp. KSM-K16. Appl Microbiol Biotechnol 1995, 43:473-481.

9. Manabe K, Kageyama Y, Morimoto T, Ozawa T, Sawada K, Endo K, Tohata M, Ara K, Ozaki K, Ogasawara N: Combined effect of improved cell yield and increased specific productivity enhances recombinant enzyme production in genome-reduced Bacillus subtilis strain MGB874. Appl Environ Microbiol 2011, 77:8370-8381.

10. Calogero S, Gardan R, Glaser P, Schweizer J, Rapoport G, Debarbouille M: RocR, a novel regulatory protein controlling arginine utilization in Bacillus subtilis, belongs to the NtrC/NifA family of transcriptional activators. J Bacteriol 1994, 176:1234-1241.

11. Belitsky BR, Sonenshein AL: Role and regulation of Bacillus subtilis glutamate dehydrogenase genes. J Bacteriol 1998, 180:6298-6305.

12. Belitsky BR, Sonenshein AL: An enhancer element located downstream of the major glutamate dehydrogenase gene of Bacillus subtilis. Proc Natl Acad Sci U S A 1999, 96:10290-10295.

13. Ali NO, Jeusset J, Larquet E, Le Cam E, Belitsky B, Sonenshein AL, Msadek T, Debarbouille M: Specificity of the interaction of RocR with the rocG-rocA intergenic region in Bacillus subtilis. Microbiology 2003, 149:739-750.

14. Commichau FM, Herzberg C, Tripal P, Valerius O, Stülke J: A regulatory protein-protein interaction governs glutamate biosynthesis in Bacillus subtilis: the glutamate dehydrogenase RocG moonlights in controlling the transcription factor GltC. Mol Microbiol 2007, 65:642-654.

15. Kada S, Yabusaki M, Kaga T, Ashida H, Yoshida K: Identification of two major ammonia-releasing reactions involved in secondary natto fermentation. Biosci Biotechnol Biochem 2008, 72:1869-1876.

16. Manabe K, Kageyama Y, Tohata M, Ara K, Ozaki K, Ogasawara N: High external $\mathrm{pH}$ enables more efficient secretion of alkaline a-amylase AmyK38 by Bacillus subtilis. Microb Cell Fact 2012, 11:74.

17. Darmon E, Noone D, Masson A, Bron S, Kuipers OP, Devine KM, van Dijl JM: A novel class of heat and secretion stress-responsive genes is controlled by the autoregulated CssRS two-component system of Bacillus subtilis. J Bacteriol 2002, 184:5661-5671.

18. Belitsky BR, Kim HJ, Sonenshein AL: CcpA-dependent regulation of Bacillus subtilis glutamate dehydrogenase gene expression. J Bacteriol 2004, 186:3392-3398.

19. Commichau FM, Wacker I, Schleider J, Blencke HM, Reif I, Tripal P, Stülke J: Characterization of Bacillus subtilis mutants with carbon sourceindependent glutamate biosynthesis. J Mol Microbiol Biotechnol 2007, 12:106-113.

20. Commichau FM, Gunka K, Landmann JJ, Stülke J: Glutamate metabolism in Bacillus subtilis: gene expression and enzyme activities evolved to avoid futile cycles and to allow rapid responses to perturbations of the system. J Bacteriol 2008, 190:3557-3564

21. Mäder U, Schmeisky AG, Flórez LA, Stülke J: SubtiWiki-a comprehensive community resource for the model organism Bacillus subtilis. Nucleic Acids Res 2012, 40:D1278-D1287. 
22. De Hoon MJ, Imoto S, Kobayashi K, Ogasawara N, Miyano S: Predicting the operon structure of Bacillus subtilis using operon length, intergene distance, and gene expression information. Pac Symp Biocomput 2004:276-287.

23. Wray LV Jr, Ferson AE, Rohrer K, Fisher SH: TnrA, a transcription factor required for global nitrogen regulation in Bacillus subtilis. Proc Natl Acad Sci U S A 1996, 93:8841-8845

24. Fisher $\mathrm{SH}$ : Regulation of nitrogen metabolism in Bacillus subtilis: vive la difference! Mol Microbiol 1999, 32:223-232.

25. Yoshida K, Yamaguchi H, Kinehara M, Ohki YH, Nakaura Y, Fujita Y: Identification of additional TnrA-regulated genes of Bacillus subtilis associated with a TnrA box. Mol Microbiol 2003, 49:157-165.

26. Belitsky BR, Wray LV Jr, Fisher SH, Bohannon DE, Sonenshein AL: Role of TnrA in nitrogen source-dependent repression of Bacillus subtilis glutamate synthase gene expression. J Bacteriol 2000, 182:5939-5947.

27. Swift RJ, Wiebe MG, Robson GD, Trinci AP: Recombinant glucoamylase production by Aspergillus niger B1 in chemostat and $\mathrm{pH}$ auxostat cultures. Fungal Genet Biol 1998, 25:100-109.

28. Jourlin-Castelli C, Mani N, Nakano MM, Sonenshein AL: CcpC, a novel regulator of the LysR family required for glucose repression of the citB gene in Bacillus subtilis. J Mol Biol 2000, 295:865-878.

29. Sonenshein AL: Control of key metabolic intersections in Bacillus subtilis. Nat Rev Microbiol 2007, 5:917-927.

30. Blencke HM, Commichau FM, Wacker I, Ludwig H, Stülke J: Regulation of citB expression in Bacillus subtilis: integration of multiple metabolic signals in the citrate pool and by the general nitrogen regulatory system. Arch Microbiol 2006, 185:136-146.

31. Chang S, Cohen SN: High frequency transformation of Bacillus subtilis protoplasts by plasmid DNA. Mol Gen Genet 1979, 168:111-115.

32. Igo MM, Losick R: Regulation of a promoter that is utilized by minor forms of RNA polymerase holoenzyme in Bacillus subtilis. J Mol Biol 1986, 191:615-624.

33. Hirai MY, Klein M, Fujikawa Y, Yano M, Goodenowe DB, Yamazaki Y, Kanaya S, Nakamura Y, Kitayama M, Suzuki H, et al: Elucidation of gene-to-gene and metabolite-to-gene networks in arabidopsis by integration of metabolomics and transcriptomics. J Biol Chem 2005, 280:25590-25595.

34. Quackenbush J: Microarray data normalization and transformation. Nat Genet 2002, 32(Suppl):496-501.

35. Rozen S, Skaletsky H: Primer3 on the WWW for general users and for biologist programmers. Methods Mol Biol 2000, 132:365-386.

doi:10.1186/1475-2859-12-18

Cite this article as: Manabe et al.: Improved production of secreted heterologous enzyme in Bacillus subtilis strain MGB874 via modification of glutamate metabolism and growth conditions. Microbial Cell Factories 2013 12:18.

\section{Submit your next manuscript to BioMed Central and take full advantage of:}

- Convenient online submission

- Thorough peer review

- No space constraints or color figure charges

- Immediate publication on acceptance

- Inclusion in PubMed, CAS, Scopus and Google Scholar

- Research which is freely available for redistribution 